Histoire de l'éducation

DEDDUCATION

$118 \mid 2008$

École et violence

\title{
A propos de deux ouvrages de Luciana BELLATALLA et Giovanni GENOVESI
}

\section{Mariella Colin}

\section{(2) OpenEdition}

1 Journals

Édition électronique

URL : https://journals.openedition.org/histoire-education/512

DOI : 10.4000/histoire-education.512

ISSN : 2102-5452

Éditeur

ENS Éditions

Édition imprimée

Date de publication : 1 avril 2008

Pagination : 159-160

ISBN : 978-2-7342-1117-4

ISSN : 0221-6280

Référence électronique

Mariella Colin, «A propos de deux ouvrages de Luciana BELLATALLA et Giovanni GENOVESI », Histoire de l'éducation [En ligne], 118 | 2008, mis en ligne le 18 mai 2009, consulté le 20 mai 2021. URL : http://

journals.openedition.org/histoire-education/512 ; DOI : https://doi.org/10.4000/histoire-education.512

Ce document a été généré automatiquement le 20 mai 2021.

(c) Tous droits réservés 


\title{
A propos de deux ouvrages de Luciana BELLATALLA et Giovanni GENOVESI
}

\author{
Mariella Colin
}

\section{RÉFÉRENCE}

BELLATALLA (Luciana), GENOVESI (Giovanni) (dir.), Scienza dell'educazione. Questioni di fondo, Firenze : Le Monnier Università, 2006. 228 p. BELLATALLA (Luciana), GENOVESI (Giovanni), Storia della pedagogia. Questioni di fondo e momenti paradigmatici, Firenze : Le Monnier Università, 2006. 364 p.

1 Ces deux manuels forment un diptyque illustrant les principes, les structures et les enjeux des sciences de l'éducation au moyen d'une présentation de l'appareil conceptuel, de la méthodologie et des paradigmes historiques propres à la discipline. Conçus et réalisés de manière similaire, complétés par des bibliographies raisonnées, des glossaires, des répertoires bio-bibliographiques et des index, ils s'articulent dans une vision d'ensemble et se complètent mutuellement. Le premier - qui est un ouvrage collectif coordonné par Luciana Bellatalla et Giovanni Genovesi - se compose d'une douzaine de chapitres, consacrés chacun à une "question de fond ", et sert de soubassement théorique et épistémologique; le deuxième, rédigé à quatre mains par les deux auteurs, retrace l'émergence et l'évolution des catégories et concepts de la pédagogie, en liaison avec les théories et les pratiques qui se sont manifestées en Occident de l'Antiquité jusqu'à nos jours.

Dans le premier volume (Scienza dell'educazione. Questioni di fondo), on commence par s'interroger sur l'appellation qui doit être considérée comme préférable, entre toutes celles qui ont été attribuées à la discipline : mieux que " pédagogie ", " philosophie de l'éducation" ou "sciences de l'éducation» (au pluriel), l'expression "science de l'éducation " (au singulier) semble aux deux coordonnateurs être la seule appellation qui garantisse sa légitimité scientifique et lui donne des assises théoriques et épistémologiques distinctes de celles des disciplines voisines (psychologie, sociologie et 
même neurosciences). Á la "science de l'éducation" se rattachent la didactique et l'histoire, tandis que le domaine de l'éducation se diversifie selon ses champs d'application, parmi lesquels sont examinés l'éducation physique, l'éducation spécialisée, la formation permanente, le jeu, l' « interculturel » et son intégration dans l'enseignement, l'éducation civique et la « citoyenneté active ».

Dans le deuxième volume (Storia della pedagogia. Questioni di fondo e momenti paradigmatici), l'évolution de la pédagogie est abordée à travers les théories qui ont marqué autant d'étapes, désignées par les deux auteurs comme des " moments paradigmatiques ». L'évolution historique est divisée en trois grandes périodes, le critère de partage étant l'apparition d'une pédagogie scientifique: des origines au XVIIe siècle (" la pédagogie avant la pédagogie »), du XVIIe à la première moitié du XIXe siècle (" vers la pédagogie comme science »), pour arriver en dernier lieu à " la pédagogie comme science de l'éducation » (de la seconde moitié du XIXe siècle à nos jours). La première période s'articule non pas autour de figures majeures de théoriciens, mais selon les catégories répondant le mieux aux modèles et aux pratiques de chaque époque : paideia pour la Grèce classique, humanitas pour l'époque romaine, caritas pour les siècles allant de l'avènement du christianisme à l'ordre féodal, auctoritas et rhetorica pour la scolastique médiévale, homo faber et homo ludens pour la Renaissance, la Réforme et la Contre-Réforme. Viennent ensuite les philosophes de l'éducation: aux grandes figures européennes comme celles de Coménius, Fénelon, Rousseau, Pestalozzi et Frœbel se joignent les éducateurs italiens, romantiques d'abord, positivistes ensuite, lorsque s'affirme la « science de l'éducation » proprement dite.

$\mathrm{Au}$ total, ces deux volumes n'apportent pas d'éclairages nouveaux mais offrent un ensemble d'informations clairement ordonné et constituent un bon outil de travail pour les étudiants auxquels ils sont destinés.

Mariella COLIN

\section{AUTEURS}

\section{MARIELLA COLIN}

